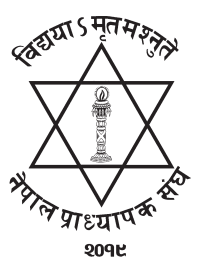

NJ: NUTA

\title{
Steps Taken for Development of Home Stay Tourism in Nepal
}

\author{
Bam Bahadur Adhikari \\ Department of History, Padmakanya Multiple Campus, Tribhuvan University. \\ Email: adhikaribambahadur@gmail.com
}

\begin{abstract}
Home stay tourism which had formally started in 1988 in form of different variety and services, is still in operation in many countries of today's world in different forms and is being operated as an important campaign to bring economic and social transformations. Home stay is being utilized as a business sector to make investments and generate income in developed countries whereas it is emphasized as a platform for production of local goods and generating employment in developing countries. Developed countries have been making huge investments in home stay and see it as a platform for business and entertainment, whereas it is being operated in different manner in developing countries. In developed countries like America, Europe, Australia, Canada etc, home stay is taken as a tool for earning high income. Developed countries emphasize on internal facilities which add to the attraction of outer environment while identifying the tourists' nature and objective and provide similar facilities. They provide required facilities for food, accommodation, studying, playing, yoga, capacity building and providing training to draw the attention of tourists. The responsibility has come upon the shoulders of related representative organizations and tourism professionals to develop home stay business as a sustainable, good quality and target based tourism. In this context, Nepalese government should develop the concept of home stay tourism in planned manner and identify its vast possibilities. It is important to have the proper direction and helpful role from the government of Nepal in home stay tourism sector which has been developing in rural areas of Nepal, along with the proper management rules and guidelines from the government's side. This article focuses in the business related to home stay and prioritizes the promotional, managerial and developmental aspects of this tourism business in Nepal.
\end{abstract}

Key word: Developing country, entrepreneurs, home stay tourism, possibility tourism development, village development in tourism,

\section{Background of the Development of Home Stay in Nepal}

Home stay tourism of Nepal should consider highlighting the living creatures, vegetation, and geographical make up and easily win the hearts of the tourists. Home stay tourism can attract tourists for study and investigating of these aspects and other tourists with the religious interests, cultural investigators, scientists, students, professors can be included in this tourism. This home stay tourism has many opportunities for increasing world cultural tourism. The historical and archaeological sites

NUTA JOURNAL, 7 (1 \& 2), 2020 : ISSN: 2616 - 017x 
like caves, temples, lakes, chaityas are found in nooks and crannies of Nepal. These sites are properly showcased while operating home stay business.

This can open the door of development and have immense possibility to emerge as powerful tool in the development of rural areas of Nepal. Maurya Emperor Ashok was the first tourist of Nepal. He had travelled religious viewpoint of Buddha place in 250 BC (Bhattarai, 2075 BS : 895). It seems important to manage home stay for strengthening it as significant means to promote economic, social and educational development in rural areas. Home stay tourism would be blessing making business for a country like Nepal mostly covered by rural areas. With the objective to make the rural tourism business systematic, Nepal has given special priority on the function of associating it with poverty alleviation since 2065 BS (2008 AD). After issuing home stay conducting procedures by the Government in 2067 (2010), business of providing lodging, food and other services to the tourists in rural communities was started in private and community level.

Though, total 214 home stays were in operation in Nepal including 103 community level and 111 private level till the mid of September 2074 (2017), even home stay business could not be a sustainable income generating business up to the long term due to lack of policy-wise provisions, physical infrastructures, conservation of natural resources and financial transparency (interview with (Prem Ghale). Till now, Sirubari Home stay situated at Andhikhola R.M. of Syangja District, Ghalegaun Home stay of Kwholasonthar R.M. of Lamjung District, Home stay of Ghandruk village of Kaski District, Namje-Thumki Home stay of Sanghurighadhi R.M. of Dhankuta District are praised as growing home stays.

\section{Statement Problems of the Study}

Although, practice of providing guest entertainment to the guest arrived to one's home was started in Rome in $405 \mathrm{BC}$ and culture of providing supports to the all of the community was prevailed also in Nepal considering the proverb 'Basudhaiba Kutumbakam' by constructing religious spots, temples, monasteries sports, platforms and planting holy fig-trees, banyan trees, farinas floribunda at the road sides, providing food and lodging to the guests free of cost regarding them as the god with the faith of gaining space (virtue) in the heaven after death, as the natural calamities like pandemics, floods, earthquakes and corona faced in time to time, tourism business along with home stay business could not be developed. Due to national policy failing to provide development of physical infrastructures for conducting home stay business, it has faced many policy oriented challenges. Hindrances created by disputes between local, provincial and federal government and unclear policy, home stay business has faced crisis. Because of fleeing about five lakh youth abroad annually, home stay business is falling down at present. Despite of these problems relating to home stay, it has been felt as an urgent necessity that the government has to forward this business rapidly. Remaining as a newest destination of tourism sector, home stay business has been found as a faultless tool. This article is best on Government plans and policy both home stay management and it's contributions for the economic development of the Country.

Objectives of the Study:

Main objective of this article is focused on simple discussion on the challenges to run home stay business under the tourism business of Nepal and to find the remedies to solve their problems. This article has expected that it will provide adequate base to the explorers, readers and researchers of 
the problems faced on implementation of home stay. Recognizing home stay business would provide considerable contribution in the rural areas of Nepal and highlighting the proverbs 'Basudhaiba Kutumbakam' and 'guests are the god,' this article has taken a vital objective to make home stay business a sustainable income generating source up to the far future.

\section{Methods of the Study}

In the course of preparing this article regarding home stay, finding legal provisions of implementation and policy, rules and legal concepts on home stay business has been explained in descriptive style. In order to highlight on the home stay business based on Nepali rural communities, using descriptive and analytic method in it, historical method has been utilized as this article being a historical study.

Both of the primary and secondary sources/materials are adopted in the article, using the sources based, multiple sources published on the books and journals are utilized comparing between two or more than two sources in order to make the sources more creditable. This article, written in A.P.A. style also has suggested searching social sources. In aggregation, as this article being a home stay business under the rural tourism is based on more qualitative technique rather than quantitative technique. Using both of inductive and deductive method, policy-wise remedies regarding implementation of home stay business has been adopted, finding/facing its challenges.

\section{Limitation of the Study}

In this article, describing on the context of the steps to run the home stay business, stability of home stay and sustainable development along with responsibilities of the owners of this business, legal procedures to run home stay, information of activities of the tourists, functions, duties and rights of the board of the directors regarding tourism, efforts made in order to home stay management, efforts has been made to highlight in brief on the subject matters regarding procedures from general process of getting the home stay registered and formation of management committee to run home stay business.

\section{Result and Discussion of the Study}

At present, the Government of Nepal has declared the policy to associate the rural activities of home stay business with poverty alleviation program by selecting some tourism-worthy places of the country for tourism development based on the communities for certain period and encouraging home stay village tourism program. In order to run such programs of rural tourism, utilizing local bodies, private sources and non-governmental sectors, in the course, local bodies, women, indigenous, madhesis, dalits, backward areas and local communities are included in the program to encourage them in sustainable conservation and promotion of religious, cultural and natural sources. (Pangeni, 2076 BS: 149) In the present contest of fleeing almost youths abroad for employment, promotion of home stay business is compulsory. Regarding potential steps to be forwarded to develop home stay business has been explained and analyzed in this article, continuously.

\section{Steps taken by the Government}

\section{Homestay law of Nepal-2010}

In Nepal, a guideline for home stay operation has been formally announced in 2010 . Government of Nepal had formulated the announcement on 03, Shrawan 2067 and had agreed to 
implement in sustainable manner. The preamble of this work procedure mentions that this home stay operation guideline, 2067 has been formulated by Ministry of tourism and civil aviation, the provisions make sure that the self employment is generated for people of rural areas, sustainable development of infrastructures for rural tourism is done to increase income generation and living standard of rural people and making rural tourism a means to involve poor, women, madhesis, indigenous people, and groups who have not been able to feel included and making the profit made from tourism sector to reach the community which were also the basis of tourism policy 2065 and to develop, promote, manage and regulate home stay tourism in both rural and urban areas (Puri, 2073 BS : P. 177).

\section{Main Objectives of Home Stay Managing}

- To operate home stay to help reach the outcome of tourism sector also in the village community of Nepal,

- To involve people from village areas in tourism service through operation of home stay tourism,

- To upgrade life standard of the community by increasing income through operation of home stay tourism,

- To utilize the means of development and create self employment through home stay at local level,

- To operate home stay in order to inform tourists about the village lifestyle and cultures,

- To provide the facility of home stay to the tourists along with unique experience of traditions, rituals, arts, culture and life style,

- To manage easy and simple environment for tourists to stay in urban areas.

\section{Classification of Home Stay}

- When at least home owners of 5 village areas manage and operate home stay in group, such home stay is called communal village home stay,

- When an individual invests and operates home stay at private level both in urban and rural areas, such home stay is called private home stay,

\section{Touristic Activities for Home Stay}

- To organize cultural programs with plays, dance, traditional and modern sports, jungle treks and scenery viewing at local level,

- To welcome tourists with caste specific and local dance and procession along with garlands made of flowers,

- To make organizers and tourists participate in different activities by organizing exhibition, festivals based on traditions and cultures in communal building and open places,

- Cultural heritages, museum of different castes, centre for domestic crafts and handicrafts, scenery viewing, jungle, wildlife and bird watching should be managed for entertaining tourists (Adhikari, 2076 BS : P. 618).

- To involve tourists in the technologies of producing agricultural produce, domestic crafts and handicrafts and help them experience traditional and modern lifestyle and cultures of village areas as well as exchange knowledge,

- While giving farewell to the tourists, the memento can be given which reflects culture of the locals and offer them garlands and hug them with all the heart,

- To follow the activities done in developed home stay and go in implementation process, 


\section{General Process for Registration of Home Stay}

- The person who wants to operate a home stay should first write an application clarifying whether it will be private or community home stay and submit this application describing project summary along with recommendation letter from local authority to the central office of Ministry of Tourism.

- In case of community home stay, at least 5 home owners should prepare written commitment to operate community home stay and submit documents along with recommendation letter from concerned authority.

- Documents like photocopies of the citizenship of the operators of home stay, photocopies of the land ownership document, and proof of building permit process should be submitted.

- The application submitted by the interested party should be checked by the central office or office of concerned authority and report in co-ordination with Nepal Tourism Board, concerned local authority and representative of health worker and monitor if the pre-requisitions are fulfilled and submit this report to the central office or office of concerned authority.

- When the report conforming that the pre-requisites have been fulfilled, the central office or concerned authority should register each home stay as a unit and provide the registration certificate.

- If the pre-requisites have not been fulfilled, time should be given for necessary reformation and then do the site inspection and help them to fulfill necessary procedure.

\section{Process for Formation of Home Stay Committee}

Those operators who want to run the community home stay, except from private home stay, should call for a simple meeting and form a home stay management and operation committee with the agreement of all those present in the meeting, as per the as such following structure: (Ibid, P. 624)

- $\quad$ Five member committee including one chairperson, one vice-chairperson and one female member along with one secretary among the present members of the community should be formed.

- Based on the households participating in the home stay management and operation committee, additional members can be involved in the community in special conditions and make it proportionate.

\section{Power and Function of Home Stay Management or Working Committee}

- To provide information about the codes and conduct that should be followed by the tourists and also about the touristic activities

- To manage residential places for tourists and guests and manage the welcoming process when they arrive.

- To register the arrival of the guests and to prepare travel packages and publicize the same.

- To exhibit and manage cultural programs which help to conserve local environment, traditions, lifestyle and culture.

- To do regular monitoring of each home stay and keep financial record of income and expenditure.

- To prepare location map for the home stay and manage and co-ordinate for medical facilities and emergency services for the tourists.

- To fix the charges for residential areas of tourists as well as for other services and put those information in chart in order to bring uniformity in the charges. 
- To prepare audit report at the end of each financial year within 35 days including number of tourists, major activities, account of income and expenditure and submit that report in central office and concerned office.

- To put information board with information about all the facilities and services and travel packages.

- To do other new creative works for development, management and promotion of home stay.

- To establish regular contact and communication with Ministry of Tourism which is the central office and also with district co-ordination committee.

\section{Formation of District Home Stay Co-ordination Committee and Its Power and Function}

District home stay co-ordination committee can be formed in each district of Nepal, with provision to remain under District Development Committee with the leadership of the member who monitors the tourism sector of concerned district development committee along with representatives of infrastructure development, health, education, communication, security, drinking water, electricity office. All the home stays existing at the local levels of each district should have the exchange of mutual help and friendship under the leadership of this district home stay co-ordination committee.

- The responsibilities, work and rights of District home-stay co-ordination committee will be as follows:

- To establish co-ordination and facilitation for the management of home stay at district level and create environment for the exchange of necessary help.

- To prepare the list of potential touristic heritage and create awareness for infrastructure development and capacity building.

- To create awareness about health facilities for tourists and establish centers for medical emergency and establish co-ordination for the same.

- To help concerned local authority to establish small infrastructures for home stay like walking trails, view tower, drinking water, health post etc.

\section{Some Works for Management of Home Stay:}

Variety of aspects is necessary in the process of management and operation of home stay. If there are no provisions of monitoring and investigation for home stay, negative elements can enter into this business. For this reason, there should be regular monitoring and investigation of home stay business. Following provisions can be done for monitoring and investigation of home stay (Adhikari, 2069 BS : 202):

- Ministry of tourism and concerned office should carry out monitoring and evaluation of the activities done by home stay management committee and each unit of home stay,

- When it is found that the standards of home stay are not maintained, such home stay should be given warnings as punishment and should be given deadline to maintain all the standards,

- The concerned organization should suspend or close the home stay that fail to maintain given standards within the deadline,

- Home stays should be renewed after their given time period is over from the same authority, they had been registered. The documents required should be submitted along with the postal ticket and after which the concerned authority should renew the home stays in every 5 years,

- Concerned authority for renewing home stay should bring effectiveness in asking for progress reports with elaborate record of income-expenditure of each 5 year, services provided by the home

NUTA JOURNAL, 7 (1 \& 2), 2020 : ISSN: 2616 - 017x 
stay and the detailed report of cost for tourism business,

- In case of community home stay, the home stay should be provided with the scientific formats where they can fill all the details of home stay while seeing the reports made by home stay operation and management committee and necessary cross checking must be done,

- Co-operation must be made for producing hoarding board, sign board, brochure, poster, CDs for advertising of home stay. Tour operators and journalists should be oriented with introductory visit and the tour packages must be made and regular activities for promotion must be given continuity,

- For marketing of home stay, policy for marketing should be prepared and the market activities related to home stay by Nepal Tourism Board and Tara Gaon Committee should co-ordinate with private travel and trekking agenies and give necessary directives for marketing activities related to home stay,

In Nepal, Industrial Profession Act, 2073, section 15 (2 cha), includes all the professions related to tourism as industry under schedule- 6 of the act. Under this schedule:

1. Tourism industry, residential areas of tourist, motel, hotel, resort and restaurants fall under no. 1,

2. Travel agency, tour operator, healing center, casino, massage spa,

3. Under adventurous sport fall skiing, gliding, water rafting, hot air ballooning, parasailing, elephant ride, bungee jumping and mountain climbing,

4. Golf course, polo, pony trekking,

5. Rural tourism, home stay and eco tourism are listed,

6. Similarly in 6, cultural, historic, conferences and sport tourism,

7. Recreational park,

8. Operation of mountain flights are also included,

The following conditions are necessary to be followed by concerned authorities for making home stay operated in Nepal to be more managed and for promoting as means of development (Prasain, 2075 BS : 119-130):

- It is imperative to present the multiethnic, multilingual It seems necessary for Government of Nepal to designate budget for the infrastructure development of home stay business and likewise state government and local level government should focus on releasing the budget for this purpose on timely manner.

- For the promotion and infrastructure development of increasing home stay in Nepal, the stakeholders should play the common role and come together in groups and remain determined to strengthen home stay tourism business

- "One state, one model home stay", this model should be developed and concrete planning and implementation of the programs should be done for operating traditional and modern home stay of international standard in all the states

- The home stay management committee spread all over Nepal and Home Stay Association Nepal (HoSAN) should come together and concentrate in taking the common goal forward.

- It seems necessary to establish mutual fund for different types of home stays like community and private home stay separately which helps in proper marketing and branding and manage the publicity aspect. For this purpose, each home stay should construct different websites incorporating their special features and unify them under the websites of Home Stay Association and do the 
promotion and marketing in integrated manner. Tourism board also should give special focus and help in promoting the activities of home stay.

- Every time the government officials go to different districts for the official trips, they should be encouraged to manage their accommodation in home stay and conduct the government level conferences, workshops, discussions and meetings in the hall of home stay.

- The meetings, seminars and workshops related to home stay sector and programs helping to make policy of the home stay should definitely be conducted in home stay and the trend of conducting home stay related programs in hotels with all the facilities, showing the reasons of security, facility and others should be stopped.

- With the help of special grants, the government should support the home stays and their current infrastructures to develop into globally recognized model home stays with all required facilities like seminar hall, security, accommodation, eateries, entertainment and transportation.

- Collaboration with NGOs and support from INGOs and diplomatic missions should be sought in order to share learning at global level.

\section{Responsibilities of Home Stay Entrepreneurs in Nepal}

Government of Nepal has brought home stay Guideline-2067 for the operation of home stay. Though this guideline is not practical and sustainable due to the lack of work experience and studies, but the policy and laws made by government should be followed by everyone. This work plan has surely given formal status to the home stay operation. This work plan was passed on Shrawan 3, 2067 and incorporated the objectives of home stay operation, classification of home stay, touristic activities of home stay, home stay management and operation committee, managerial responsibilities of the committee, provision for monitoring and inspection, renewing, and to submit report about the means of advertisement and marketing to the concerned authority are the roles of home stay operators fall under the responsibilities of home stay operators (Pangeni, 2076 BS : 150). It is every citizen's responsibility to keep the rules and regulations made by the government in their mind. Studying the potential of home stay in Nepal, this topic itself is not only the centre of attraction, but also effective means for economic, social, cultural, educational and physical transformation.

On the basis of the above mentioned things, if the home stay owners do not carry out their responsibilities and duties, the negative message will go to the public and negative mentality can be created in the public. That's why, community and private home stay operators should carry out following duties and responsibilities and give attention to these things (Puri, 2013 BS : 176):

- Location along with identity: The planning should be done while disclosing proper identity of the home stay

- Peace and security: Management of peace and security should be done by management and home stay operators.

Facilities: Location where the foreigners and internal tourists stay should have all the facilities

Residency with enough light and clean air: The guests who stay in home stay should have enough light and clean air in their rooms

Information board: Information board with all the necessary information should be hung in the visible location of home stay:

- Library: There should be management of library with suitable books for the tourists

NUTA JOURNAL, 7 (1 \& 2), 2020 : ISSN: 2616 - 017x 
- Touristic Park: Attractive touristic parks should be made for the tourists to roam around

- Delicious and nutritious food: The food made available to the guests should be nutritious and delicious

- Managed kitchen: Kitchens should be constructed in managed way at visible sight for the tourists

- Clean toilets: Toilets with proper facilities and separate ones for male and female should be managed

- Clean and plenty of water: Clean and safe drinking water and sufficient water must be provided to the tourists

- Water test: The water at home stay should be tested and made safe and clean

- Trained staffs: The staffs of home stay should be given proper training related to operation of home stay tourism business

- Storage of necessary materials: Storage of mainly organic food materials should be done for the guests

- Management of fire safety: If the incidents of fire take place in home stay, there should be provisions to mitigate the fire in time

- Electrical security: Electrical cords should not be placed haphazardly in the place of home stay and the connection should be done in secured manner

- Others: Home stay businesses should be conducted using new methods and technologies in today's changing world.

As there are many possibilities of home stay tourism in the rural areas of Nepal, the operators and management level should give focus in the proper management in this sector. As home stay business is profitable one, the rules and regulations made by the government should be followed and its impact should take the society and nation towards the path of development. Uniformity should be brought in the operation of the home stay, whether it is private or communal. The operators should not show misery while providing services to foreigner and internal guests.

\section{Stability and Sustainable Development of Home Stay in Nepal}

Home stay tourism in Nepal has potential to become a larger chunk of all the rural development which is why Nepal should think about the permanency and sustainable development of home stay. The problems existing in home stay should be solved and new ideas and skill related works should be focused for the sustainable development and permanency of home stay business. In order to make it sustainable, the conservation of environment and local cultures should be done and national and international marketing must be emphasized. Contact and coordination should be maintained with all the organizations related with home stay by organizing different seminar, workshops, trainings and focus of publicity for the expansion of home stay tourism (Kunwar, $2006 \mathrm{AD}$ : 74). The environment of home stay should be maintained in such a way that it is different from all other hotels, motels, lodge and should provide different type of relaxation and entertainment to the guests along with all the facilities to win the hearts of the tourists. Potential aspects that can provide sustainability to the home stay should be identified.

At present, rather than mere operation of the home stay, aspects that provide permanency and sustainable management of the home stay seem important. The achievements seen in home stay should be publicized and monitoring and evaluation must be done from time to time. The location for home stay should have some different identity and the findings from the study and investigation should be 
taken as basis to produce goods and marketing of such goods can make the activities of the home stay sustainable in the long run. For this, coordination should be done between central and state government and the management of marketing efforts can provide sustainability to home stay business.

Here, in this context the major things that can provide permanency to home stay business have been pin pointed: (Adhikari, $2076 \mathrm{BS}: 247$ )

- The private and community home stay operators spread all over the village areas of Nepal should be brought under one umbrella organization and all the information about the services provided should be gathered in a list and put under the website so that the targeted groups can have access to all the information online.

- Every home stay operators should co-ordinate with home stay association to produce materials for marketing and come together to distribute those materials in potential touristic markets and make strategy for publicity

- According to the strategy of targeted market, home stay business and association should participate in places like fairs/carnival and exhibitions where large number of audiences are present and the materials for publicity like visiting card, brochures, and the materials produced by the business should be marketed at large scale. The new and attractive technologies like e-mail, VOIP, mobile phone, video conferencing should be used by the home stay operators for effective marketing and publicity and the operators should make combined efforts to bring global wave in the sector of home stay tourism.

- Public relation, communication and awareness as well as lobbying and advocacy are the major aspects of home stay marketing. So, these should reach all means of communication and the media workers should be asked to promote home stay by bringing them in the location and making promotional videos. The awareness about home stay should be increased through the use of radio, television, print and online and the media workers should be provided with all the information so that the publicity can be done in full swing. The representatives of home stay who are popular should be chosen to publicize the produced materials and publicity should be done in speedily manner focusing on potential and target tourists.

- Social media platforms like face book, internet should be used rapidly for the publicity of the programs happening at present and in future. Face book can spread the information and messages to the customers rapidly and can provide feedback from the customers in short time. Every home stay has its own originality, so the branding of the originality should be done and the information on entertainment services that customers can receive in home stay should be disseminated which makes it easy to increase attractions of home stay among the target groups.

- The internal tourists like teachers coming for educational tour, students, and campaigners from non-governmental organizations, people related to trade and business should be impressed and the venue of their interests to organize trainings, seminar, and projects should be provided. This venue can be the communal building of the home stay. These communal buildings could also be the medium for publicity and publicity materials should be made for those buildings.

- Information should flow from central to local level government and vice versa and both government and private sectors should be made aware and encouraged for active involvement for the management of mutual monetary fund for home stay management 
- $\quad$ Like British prince Harry showed interest in staying at local home stay at Dalla, famous national and international personalities should be invited to visit the home stay and proper environment should be created for that. The organizations should be requested to publicize about the identity and specialties of home stay in their print media, brochure, booklet etc (Prasain, 2075 BS : 125).

- Co-ordination should be done with the organizations helping in expansion of home stay like national and international airports, ministries, ministry of health and environment, tourism board and other organizations related to tourism and basis for marketing should be searched intensively.

\section{Suggestions}

A proper intervention at policy level should be made in order to enhance and properly manage the livelihood and lifestyle of citizens through home stay tourism. This will help and contribute towards making all rural villages united for providing tourism services while also prioritizing local produce, unique presentation and use of organic foods and multicultural aspects of Nepali culture through home stay tourism for the long term conservation and development of Nepali culture. For doing this, it is important to establish, develop museum to extend ethnic, cultural and lingual aspects of Nepali culture. This should then be linked to the preservation of cultural heritage and promotion of home stays. Government of Nepal is failed to make strengthened the home stay tourism which provides income generating business at own home courtyards. The law promulgated by the Government is not at properly enforced.

A special legal provision should be started which will enable government to collect tax from all Nepalese citizens visiting foreign countries on tourist visas upon entering Nepal and the amount collected can be used to invest in infrastructure development in remote touristic destinations, promotion and marketing of these destinations and other support to the home stays in a systematic and planned way. Other similar options of resource mobilization should also be looked upon for sustainable development of quality and responsible rural tourism (Kandel, 275 BS : 149-154).

Government or local agency, responsible for regulating and operating homes stays should monitor the operating mechanism of all home stays in order to discourage activities that are against the values, ethics and guidelines of the home stays. Home stay entrepreneurs should wholeheartedly support government in this regard (Ibid, P.127).

Every home stay should efficiently manage park, electricity, trails, view point and toilets with emphasis on providing efficient health service and security system by using $5 \mathrm{P}$ campaign such as infrastructure management, water management, library establishment and park construction. Local communities living around destinations which lack in physical infrastructures such as Gosaikunda, Halesi, Pathibhara, Swargadwari, Rara, Khaptad and those around globally famous destinations such as Lumbini, Muktinath, Swargadwari, Nagarjuna and Dhorpatan should be encouraged to manage and operate properly facilitated home stays for highest benefit from tourism (Ibid, P.128).

National Planning Commission should play a leading role in properly managing home stays by strategic intervention, plan drafting, national program and making it a national priority. It should also take lead in preparing vision paper on poverty alleviation through human resource development, production process, benefit sharing and guide the activities of Ministry of tourism and Taragaon Development Committee. 
One culture museum of particular caste should exist in each state along with which national cultural museum should be established incorporating the 125 castes and 123 languages and their originality, historic and cultural heritages. The task of establishing and operation of that museum should be handed over to Tara Gaon Samiti. In order to expand this process from state to local level, concrete planning must be done for effective implementation (Ibid, P.129).

In addition to these steps, home stay operation guideline should be given shape and government should make sustainable plans and the management of home stay should be transformed in sustainable manner.

\section{Conclusion}

As there is vast possibility in development of the tourism at local level, at state and national level, proper management and development of home stay should be focused by the government. The village tourism should be made the means of development of nation. Development of the tourism sector can be the solution to the economic backwardness of the village areas. As home stay is strong basis of rural tourism, promotion of home stay should be done to attract internal and external tourism. Every aspect of tourism should be handled after gaining necessary knowledge and the concerned professionals should be well trained and create an environment for encouraging them. Economic and physical development of the tourism business owners is necessary through the means of home stay. While the inhabitants of rural area who are struggling in their compulsive situations to earn their livelihood and up lift their life standards, it becomes nation's responsibility to bring home stay as the basis for economic growth.

While searching the way for economic growth, it seems necessary to accept home stay from all the heart. This article also gives opinion that the inhabitants of the rural region can experience development and progress through management of home stay. The common people who have been marginalized and spending their lives in rural areas and the community of backward caste and groups could benefit from the home stay under rural tourism and such home stay under rural tourism needs to be managed at private and community level. It seems necessary that the central government and state government should cooperate with local government and pay attention towards making special guidelines and organize home stay in all villages of Nepal and shape the future of all the people living under absolute poverty line through the means of home stay tourism.

\section{References:}

Adhikari, B, B. (2076 BS) Paryatan Ra Bikasko Itihas. Kathmandu : Dikura Publication.

Adhikari, B, B. (2073 BS) Lamjungko Paryatanko Itihas. Kathmandu : Hamro Nawodit Pustak Bhandar. Adhikari, B, B., (2069 BS) Lamjungko Samkshipta Itihas. Kathmandu: Molung Foundation.

Adhikari, B, B., (2076 BS) Glimpses of History \& Tourism of Nawalparasi. Kathmandu : Swadesh Prakashan.

Bhattarai, G. (2075 BS) Brihat Gyankosh. Kathmandu : Ashish Book House L.td.

Kandel, Y. L. (2075 BS) "Sambriddhiko Pramukh Adhar Paryetan Bikas" Nepalma Paryatan Bikas Ra Sambriddhiko Adhar.Kendriya Paryatan Prabardhan Bibhag

Kunwar, R. (2006 AD) Tourist and Tourism. Kathmandu : International school of Tourism and Hotel 
Management.

Pangeni, B.(2019 A.D.) "Nepalma Home 'stay' (Gharbas) Paryetan Aitihasik Parichaya, Sanchalan Ra Chunauti" HISAN. (Journal of History Association of Nepal) No.1. Vol.5. December. pp. 142156.

Pathak, R. S. (2012 A.D.) Tourism Geography (With Special Reference to Nepal) Kathmandu : Uma Pathak.

Prasain, A. (2075) "Home stay Abhyas Ra Nepalma Sambhabyata" Nepalma Paryatan Bikas Ra Sambriddhiko Adhar.Kendriya Paryetan Prabardhan Bibhag. NCP UMl.pp. 119-130.

Puri, U. (2073 BS) Paryatan, Bikas Ra Nepal. Kathmandu : Taleju Prakashan... NCP UMl. pp.149-154. 